\title{
RESGATANDO RAÍZES: INVENTÁRIO DE REFERÊNCIAS CULTURAIS DE SÃO JOSÉ DE PIRANHAS-PB
}

\author{
REDEEMING ROOTS: INVENTORY OF CULTURAL REFERENCES OF \\ SÃO JOSÉ DE PIRES-PB
}

\author{
Rafaelle Aparecida Figueiredo Gomes ${ }^{1}$ \\ Emanoella Bella Sarmento Salgueiro Eliziário Matias ${ }^{2}$ \\ Mirela Davi de Melo $^{3}$ \\ Isabel Sobral de Abreu e Lima ${ }^{4}$ \\ Pollyanna Priscila de Souza Lima ${ }^{5}$ \\ Elysson Marcks Gonçalves Andrade ${ }^{6}$
}

RESUMO: OBJETIVO: Construir um inventário que reúna fontes documentais materiais e imateriais a respeito das origens da cidade de São José de Piranhas, de modo a criar uma referência para que os habitantes da cidade conheçam sua história. MÉTODO: Para a realização da pesquisa será aplicada a metodologia desenvolvida pelo IPHAN (Instituto do Patrimônio Histórico e Artístico Nacional) e descrita no Manual de Aplicação do INRC (Inventário Nacional de Referências Culturais), que consiste basicamente em estudos de campo na qual serão coletadas informações por meio de fichas de campo, questionários, fotografias e gravações audiovisuais e sonoras. Deste modo as informações obtidas permitirão a documentação dos bens relevantes para os moradores locais e os significados contidos neles. RESULTADOS E DISCUSSÃO: Muitos momentos históricos da cidade foram relatadas, eles eram praticadas pelas pessoas em São José de Piranhas, que contavam com momentos culturais, edifícios, lugares e trabalhos. A cultura da realização de celebrações, sempre ocorriam no mês de março; As edificações contavam com: Igreja matriz, Conselho Municipal e Cadeia, Usina Tibagy, Prédio dos Correios, Antigo Hotel, Prefeitura, Mercado Público, Residência de Antônio Gomes Barbosa, Igreja Nova e Associação dos Pescadores; Os lugares: Açude Engenheiro Ávidos, Antigo Cemitério e Praça da Matriz; E uma das maiores atividades exercidas em São Jose de Piranhas era o oficio da pesca. CONCLUSÃO: Com isso, espera-se disponibilizar um material que poderá

\footnotetext{
${ }^{1}$ Graduada em Arquitetura e Urbanismo pela Faculdade Santa Maria, Cajazeiras, Paraíba.

2 Docente da Faculdade Santa Maria, Cajazeiras, Paraíba.

${ }^{3}$ Docente da Faculdade Santa Maria, Cajazeiras, Paraíba.

4 Docente da Faculdade Santa Maria, Cajazeiras, Paraíba.

5 Docente da Faculdade Santa Maria, Cajazeiras, Paraíba.

${ }^{6}$ Docente da Faculdade Santa Maria, Cajazeiras, Paraíba.
} 
aproximar os indivíduos de seu patrimônio e fortalecer o sentimento de pertencimento com o lugar em que vivem, servindo de referência para trabalhos futuros e para pessoas interessadas na história de São José de Piranhas.

DESCRITORES: São José de Piranhas; Patrimônio Histórico; Inventário; Preservação.

ABSTRACT: The present work refers to the construction of an inventory of cultural references of the city of São José de Piranhas, located in the interior of Paraíba, approximately $480 \mathrm{~km}$ from the capital. In the 1930s, the city was transferred to another locality, for the construction of a dam, to ease the problems caused by the dry rectors of the time. After the transfer, many documents and records have been lost and so there is currently a shortage of documents for this period. In view of this, it is proposed to gather the various documentary sources that still exist about this part of the city's history, aiming to build a new documentary source, so necessary for the residents themselves to come back to their origins, knowing and recognizing themselves from of the heritage presented and the meaning they contain. The methodology used to carry out the research will be a method developed by IPHAN (Institute of National Historical and Artistic Heritage) and described in the Manual of Application of the INRC (National Inventory of Cultural References), which consists of field studies that will collect information by field records, questionnaires, photographs and audio-visual and sound recordings. In this way, the information obtained will allow the documentation of the relevant heritage to the local residents and the meanings contained therein. With this, it is hoped to make available a material that can bring people closer to their cultural roots and strengthen their sense of belonging to the place where they live, serving as a reference for future works and for people interested in the history of São José de Piranhas.

DESCRIPTORS: São José de Piranhas; Historical Patrimony; Intangible Heritage; Inventory; Preservation. 


\section{INTRODUÇÃO}

Há anos, muito se discute a respeito do patrimônio e de como sua preservação é relevante pelo fato de que os bens trazem consigo uma infinidade de significações acumuladas ao longo dos tempos que podem ajudar a construir a história de uma sociedade, uma vez que as produções de um povo expressam sua cultura e identidade. Logo, quando se é preservado e valorizado, é possível que isso seja propagado e disseminado para as futuras gerações que terão a oportunidade de conhecer suas origens de forma mais próxima, pois o contato físico com o patrimônio pode levar a uma fortificação do sentimento de pertencimento e reconhecimento dos indivíduos com a sua história.

O tipo de patrimônio com definição mais antiga, discutida e consolidada tratase do patrimônio histórico e artístico ou patrimônio material. Considerando que patrimônio são bens herdados de familiares, contendo valor e significação para um grupo de pessoas, o patrimônio histórico e artístico vem a ser bens representativos de um povo de determinado lugar (povoado, vila, cidade, nação) e que tenham relevância seja por estar relacionado a momentos históricos importantes, por possuir grande valor arquitetônico/artístico ou por testemunhar a evolução (histórica, dos modos de produção, etc.) de determinado povo. Inicialmente, eram incluídos nessa categoria bens edificados imponente e monumentais, que fossem considerados representativos de toda a nação. Excluía-se assim bens que não possuíssem grande qualidade arquitetônica ou que contivessem importância a nível local.

Ao longo do tempo a noção de patrimônio passou por diversas reformulações, fazendo com que se destacasse e ganhasse um novo olhar o patrimônio imaterial que, apesar de existir, era pouco discutido até então. Nesta categoria inclui-se bens móveis e intangíveis, como celebrações, festividades, lugares de significação cultural, modos de produção, danças, entre outros similares. Isso implica uma maior abrangência deste conceito, abarcando uma maior quantidade e diversidade de bens, inclusive os mais simples e de importância para determinada parcela da 
sociedade. Juntamente com esse fato, observa-se também uma valorização da história local, à medida em que o patrimônio de pequenas cidades, povoados, vilas e das minorias tidas como menos importantes, passam a ganhar atenção.

Por ser relativamente novo e por ser multidisciplinar, envolvendo várias áreas de estudo diferentes, o patrimônio imaterial tem sido muito discutido principalmente nos últimos anos. Até os anos 2000, por exemplo, ainda buscava-se definir a melhor forma de salvaguarda para esse tipo de bem. O patrimônio material tem uma forma de salvaguarda bem definida, consolidada e que vem sendo aplicada há muito tempo. Já a ferramenta de salvaguarda do patrimônio imaterial foi definida há poucos anos e encontra-se em constante revisão de modo a aperfeiçoar a metodologia aplicada.

Em todo caso, a preservação do patrimônio imaterial, assim como do material, serve para registrar e propagar a história de um povo para perdurar ao longo dos anos e ser acessível para as futuras gerações. No entanto, para que isso ocorra, é necessário que haja uma preocupação voltada não só à preservação como à conservação desses bens. Enquanto que a preservação compreende uma série de medidas tomadas visando, direta ou indiretamente, à permanência daquele bem a longo prazo, a conservação consiste em cuidados específicos que tenham como objetivo prolongar a vida útil do bem materialmente. Dessa forma, são considerados cuidados de conservação as reparações, restaurações, adaptações, reconstruções, entre outros.

A conservação do patrimônio material depende em sua maioria da resistência dos materiais utilizados na sua construção e da manutenção que se dá a esse bem no decorrer do tempo. Além disso, os registros fotográficos, audiovisuais, a memória coletiva das pessoas ainda pode contribuir para a conservação desse tipo de bem. Já o patrimônio imaterial é bem mais frágil por depender, muitas vezes, apenas da propagação oral entre os praticantes ou conhecedores de tal atividade, prática ou lugar.

Havendo essa dificuldade em conservar, pode-se perceber que além de importante torna-se urgente a salvaguarda de determinados bens imateriais, principalmente se forem observadas a escassez documental e uma progressiva diminuição da quantidade de indivíduos que detém conhecimento a respeito desses 
bens. O registro pode garantir que, por mais que a prática não mais ocorra ou o bem não mais exista, ainda assim seja possível conhecer e acessar as informações obtidas enquanto havia detentores desse conhecimento.

Diante disso, este trabalho tem como intuito abordar a preservação do patrimônio da cidade de São José de Piranhas por meio dos bens materiais e imateriais, vigentes e em memória, e das significações contidas nesses bens para os moradores locais. Com o objetivo de construir um inventário que reúna fontes documentais materiais e imateriais a respeito das origens da cidade de São José de Piranhas, de modo a criar uma referência para que os habitantes da cidade conheçam sua história.

\section{MÉTODO}

A metodologia seguida foi a recomendada pelo IPHAN, descrita detalhadamente no Manual de Aplicação do INRC (IPHAN, 2000). Porém, para acessar tal documento fez-se necessário observar as instruções presentes na Instrução Normativa oo 001 (IPHAN, 2009). Segundo 0 artigo $1^{\circ}$ da referida normativa, seu objetivo é de "instituir parâmetros gerais de licenciamento para a utilização do Inventário Nacional de Referências Culturais (INRC)". Com o intuito de regular seu uso, são apresentadas diversas recomendações, que se tornaram necessárias diante do grande aumento na demanda, nos últimos anos, com relação à utilização desta ferramenta para levantamentos de bens culturais diversos.

O levantamento preliminar deste trabalho consiste em uma etapa de conhecimento prévio e superficial da área a ser inventariada, visando a coletar informações básicas que sirvam de suporte para o desenvolvimento das etapas seguintes. Seria a fase considerada exploratória, levantando dados presentes na bibliografia, características físicas do espaço por meio de observação e sondagem dos conhecimentos que a população detém por meio de conversa prévia, contribuindo assim para a delimitação do território (ou sítio) e da amostra da população. 
Para o presente trabalho foi considerado levantamento preliminar um trabalho de pesquisa desenvolvido na disciplina de Estágio Supervisionado Acadêmico, no ano de 2018, no curso de Arquitetura e Urbanismo da Faculdade Santa Maria, no qual foi possível coletar dados extremamente relevantes para o desenvolvimento deste trabalho.

Os critérios de escolha da amostra dessa população foram 0 de conhecimento a respeito da história da cidade no período de interesse da pesquisa (enquanto a cidade de São José de Piranhas estava inserida naquela localidade), aproveitando-se todo e qualquer tipo de informação a respeito da cidade antiga, desde que um mesmo depoimento fosse relatado de forma semelhante por vários moradores, ou seja, que suas visões viessem a convergir, seja uma memória ou informação comum a uma parcela relativa daquele grupo. De modo a manter o anonimato dos sujeitos participantes, estes foram tratados pelas iniciais dos seus respectivos nomes.

\section{RESULTADOS E DISCUSSÃO}

A formação do território correspondente a antiga São José de Piranhas foi resultado da ação de pessoas que foram requerendo terras em uma área considerada abandonada pela Casa da Torre de Garcia D'ávila. Segundo Tavares, iniciou-se quando "[...] o capitão Vital Vieira da Costa obteve a primeira sesmaria na localidade [...]" e em sequência "Francisco Xavier de Miranda requereu o sítio São José o qual estava abandonado pela Casa da Torre e na sede de sua fazenda, surgiu o povoado que deu origem a cidade de São José de Piranhas" (1982, p. 275).

À medida em que essas terras foram sendo requeridas construiu-se várias fazendas, de modo que o conjunto destas naturalmente formou o Sítio São José. Pelo fato desse sítio se situar às margens do rio Piranhas, o povoado recebeu o nome de São José de Piranhas. De acordo com Vieira (2016, p. 45), o desenvolvimento da configuração urbana de São José de Piranhas se deu com a construção de casas no entorno da capela São José. 
A vila foi emancipada politicamente em 24 de setembro de 1885, data de fundação da cidade. Nessa época, possuía diversos prédios públicos necessários ao funcionamento da cidade e a partir dos anos 20 recebeu ainda mais investimentos sendo considerada uma cidade importante na microrregião em que ela ocupa, fato esse sendo reafirmado pelas palavras de Vieira quando expõe que,

"[...] as numerosas fazendas de criação de gado e de produção de algodão, milho, feijão e arroz se espalharam pela região. Esse suporte econômico contribuiu para que a povoação de São José de Piranhas despontasse como um importante centro de comércio, interligando-a, inclusive, com a florescente povoação de Cajazeiras" (VIEIRA, 2016, p. 45).

Porém, em 1922, com a notícia de que seria construída uma barragem e sua construção implicaria no alagamento de parte da cidade quando a barragem atingisse sua capacidade máxima, esse desenvolvimento cessou e os esforços dos moradores e autoridades se voltaram para a construção dos prédios públicos, comércios e residências alguns metros mais afastados da área que estava comprometida para a construção da barragem.

Mesmo diante desse problema, seu desenvolvimento continuou, principalmente após serem noticiados que as obras da barragem foram paralisadas, poucos anos após seu início. Dada sua importância, nos anos 30 durante o governo de Getúlio Vargas, a cidade recebeu uma agência dos correios, que foi um modelo replicado em vários pontos da região Nordeste. Mas, enquanto a cidade crescia e se desenvolvia, foi crescendo paralelamente a isso um problema: a seca.

Afetando vários estados do Nordeste, foi uma questão a ser tratada pelo governo de Getúlio. Tendo como ministro da viação e obras públicas o paraibano José Américo de Almeida, a solução adotada foi a construção de barragens em várias cidades do estado. Voltaram então as obras para a construção do açude Engenheiro Ávidos, mais conhecido como Boqueirão, construído na região de São José de Piranhas.

Mesmo havendo a opção de fazer com que a cidade continuasse se desenvolvendo no sentido oposto às águas da barragem, parte alta do território, 
como a própria população já vinha fazendo, os políticos locais decidiram transferir a cidade para outra localidade, distante $10 \mathrm{~km}$ ao sul. Após a relocalização da cidade os moradores que possuíam melhores condições financeiras mudaram-se de imediato para a nova cidade (inicialmente chamada de "Jatobá" devido à enorme quantidade dessa árvore na região e só posteriormente herdou o nome da antiga cidade). Por outro lado, a maioria dos moradores da antiga cidade permaneceu no local, alguns por não possuir condições financeiras de construir suas casas em um outro lugar e outros por não sentirem vontade de se desligar do lugar onde nasceram e se criaram. Além disso, muitas dessas pessoas fariam uso da barragem como fonte de renda, por meio da pesca e agricultura.

Como a cidade agora estava em pleno funcionamento em um outro lugar, totalmente planejada e construída com recursos provenientes do governo federal, os prédios públicos da antiga cidade foram aos poucos sendo desativados, servindo à população resistente como fonte de materiais de construção para que fossem levantadas suas novas casas afastadas a alguns metros de onde se previa a inundação provocada pela cheia da barragem. Algumas poucas edificações se mantiveram intactas por anos, porque mesmo após ter sido finalizada a construção da barragem (1936) somente em 1947 a barragem encheu, encobrindo ruas e edificações importantes.

Desde então o que se tem do conjunto urbano que ali havia são ruínas de edificações - ora cobertas pelas águas da barragem e vegetação em períodos chuvosos, ora expostas em períodos de seca - que, apesar de não terem sido atingidas pelas águas sofreram a ação humana sendo desconstruídas aos poucos com a retirada de seus materiais ou sendo completamente reformadas, perdendo parcial ou totalmente as suas características originais.

Um dos pontos principais deste trabalho envolve o levantamento das produções arquitetônicas da localidade, mesmo a maior parte delas estando descaracterizadas, em ruínas ou apenas em memória. Apesar de não possuir nenhuma monumentalidade, constituem o conjunto urbano e detém memórias e fortes significações do povo que nela vive, bem como para os habitantes da atual cidade de São José de Piranhas. 
O grupo tratado nesse trabalho (habitantes da cidade de São José de Piranhas) está desenvolvendo naturalmente um processo de esquecimento do seu patrimônio cultural devido os episódios que a cidade passou, o que enfraquece cada vez mais o reconhecimento da sua identidade cultural, que está intimamente ligado com o histórico do local que é objeto de estudo da pesquisa.

A vila corresponde ao território em que, até o final da década de 1930, esteve instalada a cidade de São José de Piranhas. Em 1937 a cidade foi transferida para outra localidade, pois seria atingida pelas águas da Barragem de Engenheiro Ávidos, após sua construção. E, de fato, após a primeira cheia da barragem, em 1947, parte das edificações foram cobertas pelas águas. Desde então, os vestígios da antiga cidade ficam submersos, ressurgindo apenas em períodos de seca prolongados.

Pelo fato de passar a maior parte do tempo encoberta, a origem da antiga cidade de São José de Piranhas fica esquecida pela maior parte de seus habitantes, o que acaba distanciando os indivíduos de sua história. Por esta razão esta área foi escolhida, com o intuito de apreender os significados existentes nos vestígios que resistiram a ação das águas e do tempo, a fim de criar uma referência para que seus habitantes possam resgatar e reconhecer o seu patrimônio cultural.

Alguns momentos históricos da cidade eram muito praticadas pelas pessoas em São José de Piranhas, que contavam com momentos culturais, edifícios, lugares e trabalhos. A cultura da realização de celebrações, sempre ocorriam no mês de março; As edificações contavam com: Igreja matriz, Conselho Municipal e Cadeia, Usina Tibagy, Prédio dos Correios, Antigo Hotel, Prefeitura, Mercado Público, Residência de Antônio Gomes Barbosa, Igreja Nova e Associação dos Pescadores; Os lugares: Açude Engenheiro Ávidos, Antigo Cemitério e Praça da Matriz; E uma das maiores atividades exercidas em São Jose de Piranhas era o oficio da pesca.

\section{CONCLUSÃO}

De modo a enriquecer a experiência e possibilitar novas interpretações da história do lugar, foram feitas pesquisas bibliográficas com relação ao contexto 
histórico em que aqueles bens foram construídos ou estavam em vigor, visando a identificar relações que pudessem justificar de alguma forma sua existência e compreender suas condições de ocorrência (de que modo foi construída ou em que ocasião ocorria determinado bem).

Diante da falta de conhecimento por parte de muitos piranhenses com relação ao histórico da cidade de São José de Piranhas, recomenda-se que seja feito um trabalho de divulgação das pesquisas realizadas até então a respeito da formação da cidade até o ano de sua transferência para a atual localidade.

Além disso, recomenda-se fortemente que as pesquisas sejam continuadas para que seja ampliada a quantidade de informações que se obteve até o momento, e que isso ocorra com certa urgência considerando que trata-se de um patrimônio frágil que está em constante ameaça tanto pelo alto grau de degradação em que se encontra como também pela escassa quantidade de pessoas que ainda podem informar sobre as memórias mais antigas do lugar, tendo em vista que essa quantidade tende a diminuir se esses trabalhos não forem acelerados.

\section{REFERÊNCIAS BIBLIOGRÁFICAS}

AESA. Volume de Açudes. Disponível em <www.aesa.pb.gov.br>. Acesso em 12 de abril de 2019.

ALMEIDA, José Américo de. A Paraíba e seus problemas. 3.ed. Paraíba: A União, 1980.

ANDRADE, Cyntia. Lugar de memória... memórias de um lugar: patrimônio imaterial de Igatu, Andaraí, BA. Pasos - Revista de Turismo e Patrimônio Cultural. Espanha, v. 6, 2008.

ARANTES, A. A.; RAMASSOTE, R.; MORAIS, S. S. Trajetória e Desafios do Inventário Nacional de Referências Culturais (INRC): entrevista com Antônio Arantes. In: Revista CPC (USP), 2015.

ARAÚJO, Maria Pia. Palitot Gomes. Antônio Gomes Barbosa: 100 anos in Memorian (1901 2001). João Pessoa: Projeto Gráfico Tony Onofre, 2001.

BARRETO, Paulo Thedim. Casas de Câmara e Cadeia. Revista do SPHAN no 10. Rio de Janeiro, 1947.

BRASIL. Constituição (1988). Artigo 216. Define patrimônio cultural brasileiro. Brasília: Planalto do Governo. Disponível em: <https://www.senado.leg.br/atividade/const/con1988/CON1988_05.10.1988/art_216_.asp>. Acesso em: 28 set. 2018.

BRASIL. Constituição (1937). Decreto-Lei № 25 de 30 de novembro de 1937. Organiza a 
proteção do patrimônio histórico e artístico nacional. Brasília: Planalto do Governo. Disponível em: <http://www.planalto.gov.br/CCIVII_03/Decreto-Lei/Del0025.htm>. Acesso em: 14 out. 2018.

BRASIL. Constituição (1988). Decreto-Lei № 3.551 de 4 de novembro de 1988. Institui o Registro de Bens Culturais de Natureza Imaterial que constituem patrimônio cultural brasileiro, cria o Programa Nacional do Patrimônio Imaterial e dá outras providências. Brasília: Planalto do Governo <http://www.planalto.gov.br/ccivil_03/decreto/d3551.htm>. Acesso em: 19 out. 2018.

CBDB. A história das barragens no Brasil, Séculos XIX, XX e XXI: cinquenta anos do Comitê Brasileiro de Barragens. Rio de Janeiro: CBDB, 2011.

CORÁ, Maria Amelia Jundurian. Do Material ao Imaterial: Patrimônio Culturais do Brasil. São Paulo: PUC-SP, 2011.

CUNHA, João Rolim da. São José de Piranhas, Apontamentos para a sua história. João Pessoa: A União, 1999.

FILHO, Nestor Goulart Reis. Quadro da arquitetura no Brasil. 4.ed. São Paulo: Perspectiva, 1978.

FONSECA, Maria Cecília Londres. O patrimônio em processo: trajetória da política federal de preservação no Brasil. 2. ed. Rio de Janeiro: UFRJ/Minc-Iphan, 2005.

FREIRE, Cristina. Além dos mapas: Os monumentos no imaginário urbano contemporâneo. São Paulo: SESC: Annablume, 1997.

FREIXO, Hugo Marinho. Coretos do Concelho de Viana do Castelo: Contributos para a sua caracterização e valorização. Dissertação (Mestrado Integrado em Arquitetura e Urbanismo) Escola Superior Gallaecia. Vila Nova de Cerveira, 2017. Disponível em: < http://hdl.handle.net/10400.26/22973>. Acesso em: 12 mai. 2019.

FREIXO, Hugo Marinho. Educação Patrimonial: histórico, conceitos e processos. Brasília: Instituto do Patrimônio Histórico e Artístico Nacional, 2014.

GIL, Antônio Carlos. Como elaborar projetos de pesquisa. 4. ed. São Paulo: Atlas, 2002.

IPHAN, COPEDOC. Dicionário IPHAN de Patrimônio Cultural. Rio de Janeiro: Cadernos de pesquisa e documentação do IPHAN, 2008.

IPHAN. Carta de Fortaleza. 1997. Disponível em: <http://portal.iphan.gov.br/uploads/ckfinder/arquivos/Carta\%20de\%20Fortaleza\%201997.pdf>.

Acesso em: 28 set. 2018.

IPHAN. Instrução Normativa no 001 de 2 de março de 2009. Dispõe sobre as condições de autorização de uso do Inventário Nacional de Referências Culturais (INRC). Disponível em: <http://portal.iphan.gov.br/uploads/ckfinder/arquivos/Instrucao_Normativa_001_2009.pdf>. Acesso em: 25 out. 2018.

IPHAN. Referências Culturais: bases para novas políticas de patrimônio. In: Manual de aplicação do INRC. Brasília: IPHAN, 2000.

LEITÃO, Deusdedit. São José de Piranhas: Notas para sua história. João Pessoa: UniGraf, 1985.

LIMA, Messias Ferreira de. São José de Piranhas: Um pouco de sua história. Paraíba: Editora REAL, 2010. 
LIMA, Messias Ferreira de. São José de Piranhas, Datas e notas. Paraíba: Editora REAL, 2017.

NASCIMENTO, José Sérgio Dantas do. As Dinâmicas das Paisagens Urbanas nas Praças Aristides Lobo e Pedro Américo em João Pessoa (PB). Monografia. Universidade Federal da Paraíba. João Pessoa, 2017. Disponível em: $<$ http://www.ccen.ufpb.br/ccblg/contents/documentos/bacharelado/trabalhos-de-conclusao- decurso-2017.1/jose-sergio-dantas-do-nascimento.pdf>. Acesso em: 12 mai. 2019.

NORA, Pierre. Entre história e memória. A problemática dos lugares. Projeto História. São Paulo: PUC, vol. 10, n. 10, 1993.

NORBERG-SCHULZ, Christian. O Fenômeno do lugar. In: NESBITT, Kate. (org.). Uma Nova Agenda para a Arquitetura. Antologia Teórica 1965-1995. São Paulo: Cosac Naify, 2006.

TAVARES, João de Lyra. Apontamentos para a história territorial da Parahyba. v. CCXLV. Coleção Mossoroense, Edição Fac-similiar, 1982.

TUAN, Yi-Fu. Espaço e lugar: a perspectiva da experiência. Tradução: Lívia de Oliveira. São Paulo: DIFEL, 1983.

TUAN, Yi-Fu. Topofilia: um estudo da percepção, atitudes e valores do meio ambiente. São Paulo: DIFEL, 1980.

UNESCO. Recomendação Paris. $2003 . \quad$ Disponível em: <http://portal.iphan.gov.br/uploads/ckfinder/arquivos/Recomendacao\%20Paris\%202003.pdf>. Acesso em: 28 set. 2018.

VIEIRA, José Marconi Gomes; LIMA, Messias Ferreira de. História da paróquia de São José de Piranhas: 174 anos de fundação (1840-2014). João Pessoa: A União, 2014.

VIEIRA, José Marconi Gomes; LIMA, Messias Ferreira de. Antônio Gomes Barbosa: a biografia. João Pessoa: Mídia Gráfica e Editora Ltda, 2016. 